\title{
DSM-5 Alcohol Use Disorder Severity as a Function of Sexual Orientation Discrimination: A National Study
}

\author{
Sean Esteban McCabe (D), Tonda L. Hughes, Brady T. West, Phil Veliz, and Carol J. Boyd
}

\begin{abstract}
Background: Sexual minorities are more likely than their heterosexual counterparts to develop alcohol use disorder (AUD), and understanding the underlying reasons for this heightened risk is a public health priority. This study examined relationships between sexual orientation discrimination and DSM-5 AUD severity.

Methods: The 2012 to 2013 National Epidemiologic Survey on Alcohol and Related Conditions III conducted in-person interviews with a nationally representative sample of U.S. adults $(N=36,309)$. Approximately $2.8 \%$ of the target population self-identified as lesbian, gay, or bisexual, $3.1 \%$ had at least 1 past-year same-sex sexual partner, and $8.3 \%$ reported same-sex sexual attraction.

Results: Adults who identified as lesbian, gay, bisexual, heterosexual with same-sex attraction and/ or current same-sex sexual partners, and those not sure of their sexual identity, had higher rates of individual DSM-5 AUD criteria than heterosexual-identified adults with only opposite-sex attraction and sexual partners. Respondents who were bisexual or unsure of their sexual identity consistently had the highest probabilities of endorsing each of these AUD criteria relative to the other subgroups. Differences in AUD severity across sexual orientation subgroups were much larger among women than among men. Sexual minorities who experienced higher levels of sexual orientation discrimination had significantly higher levels of AUD severity than sexual minorities who experienced lower levels or no discrimination. In particular, greater levels of sexual orientation discrimination increased the odds of impaired control criteria and pharmacologic criteria. Associations between prior-to-past-year sexual orientation discrimination and AUD severity were not as robust as those involving past-year discrimination.

Conclusions: Sexual minorities are at substantially greater risk of severe DSM-5 AUD, and this is particularly true among those who experience high levels of sexual orientation discrimination. Findings indicate that proximal experiences of discrimination are more salient than distal experiences. AUD treatment should address recent sexual orientation discrimination given that such experiences are associated with more severe AUD.
\end{abstract}

Key Words: Sexual Orientation, Alcohol Use Disorder, DSM-5, Severity, Discrimination.

A LCOHOL USE DISORDER (AUD) carries a large health, social, and economic burden worldwide (World Health Organization, 2014). In the United States alone, more than 65 million adults meet the criteria for an AUD in their lifetime (Grant et al., 2015b). There is a wealth of research

From the Center for the Study of Drugs, Alcohol, Smoking, and Health (SEM, PV, CJB), School of Nursing, University of Michigan, Ann Arbor, Michigan; Institute for Research on Women and Gender (SEM, PV, CJB), University of Michigan, Ann Arbor, Michigan; Institute for Healthcare Policy and Innovation (SEM), University of Michigan, Ann Arbor, Michigan; Center for Human Growth and Development (SEM, CJB), University of Michigan, Ann Arbor, Michigan; Department of Psychiatry (TLH), School of Nursing, Columbia University, New York, New York; Survey Research Center, Institute for Social Research (BTW), University of Michigan, Ann Arbor, Michigan; and Addiction Center (CJB), Department of Psychiatry, University of Michigan, Ann Arbor, Michigan.

Received for publication June 7, 2018; accepted January 8, 2019.

Reprint requests: Sean Esteban McCabe, PhD, Center for the Study of Drugs, Alcohol, Smoking, and Health, School of Nursing, University of Michigan, 400 N. Ingalls, Ann Arbor, MI 48109; Tel.: 734-615-8840; Fax: 734-615-2931; E-mail: plius@umich.edu

(C) 2019 by the Research Society on Alcoholism.

DOI: 10.1111/acer.13960 indicating that lesbian, gay, and bisexual individuals (also referred to as sexual minorities) are at heightened risk of heavy drinking and AUD (Cochran and Mays, 2006; Drabble et al., 2005, 2013; Green and Feinstein, 2012; Hughes and Eliason, 2002; Hughes et al., 2010a,b; Kerridge et al., 2017; McCabe et al., 2004, 2005, 2009; Medley et al., 2016). Enhancing understanding of the underlying reasons for health disparities among sexual minorities is a public health priority (Institute of Medicine, 2011). Although researchers increasingly consider sexual orientation an important area of inquiry, to our knowledge there have been no investigations of potential risk factors for greater AUD severity among sexual minorities using DSM-IV or DSM-5 criteria.

Many studies on sexual minority health have posited that disparities are related to sexual minority stress (Cochran et al., 2003; Drabble et al., 2005; Hughes and Eliason, 2002; Meyer, 2003), yet no large-scale studies have directly tested this proposition for AUD severity among sexual minorities. Although sexual orientation includes multiple dimensions (e.g., attraction, behavior, and identity), the few national alcohol studies that have assessed sexual orientation have generally focused on only 1 or 2 dimensions. Findings from 
these studies suggest that sexual identity is a more salient predictor of AUD than sexual behavior (Drabble et al., 2013; McCabe et al., 2009; Talley et al., 2015). For instance, McCabe and colleagues (2009) found greater odds of DSMIV alcohol dependence among women and men who identified as lesbian/gay than those who identified as heterosexual, but found no such differences based on sex of sexual partners. Although sexual minority women and men who "identify" as lesbian/gay may have greater exposure to discrimination and other forms of minority stress than those who engage in same-sex behavior or have same-sex attractions but do not identify as a sexual minority, prior studies emphasize the importance of assessing multiple measures of sexual orientation (Drabble et al., 2013; McCabe et al., 2009; Talley et al., 2015).

There is evidence that risk of heavy drinking and AUD differs based on sex (Eisenberg and Wechsler, 2003; Hughes et al., 2016; McCabe et al., 2005, 2009). Although studies in the United States and elsewhere have, almost without exception, found higher rates of heavy drinking and AUD among sexual minority men and women, the associations are consistently stronger for sexual minority women (Eisenberg and Wechsler, 2003; Hughes et al., 2010a, 2016; McCabe et al., 2005, 2009). Thus, it is important to consider potential sex differences in research focusing on AUD among sexual minorities (Hughes et al., 2016; Institute of Medicine, 2011).

The current study is based on the premise that sexual minorities are at heightened risk of AUD as a consequence of environmental, institutional, and social factors associated with being part of a stigmatized and marginalized population (e.g., Herek, 2009; Institute of Medicine, 2011; McCabe et al., 2010). The minority stress model describes how discrimination, social stigma, prejudice, and victimization contribute to heightened risk of AUD among sexual minorities (Meyer, 1995, 2001, 2003). Meyer (2003) proposed a number of processes directly related to minority stress, including stressful events and conditions such as exposure to harassment, victimization, and violence; expectations of such events and the vigilance that this expectation requires; internalization of negative societal attitudes about homosexuality; and concealment of one's sexual orientation. Sexual orientation discrimination has been shown to be associated with substance use and compromised mental health (e.g., Bostwick et al., 2014; Hatzenbuehler et al., 2009, 2010; Lee et al., 2016; Lewis et al., 2003; Mays and Cochran, 2001; McCabe et al., 2010, 2017; Slater et al., 2017).

Although evidence suggests that exposure to sexual minority stressors, such as discrimination, is associated with substance use and poor health, a number of gaps and limitations remain in the literature. As noted above, most studies using nationally representative samples do not include all 3 major dimensions of sexual orientation. In addition, existing studies have focused primarily on the prevalence of AUD and have not considered AUD severity. Moreover, the majority of existing studies include relatively small samples that prohibit examinations of sex differences, individuals who are "not sure" about their sexual orientation, and risk factors associated with severe AUD among sexual minorities. To address these gaps, theory-driven studies are needed to enhance understanding of AUD severity among sexual minorities and to better inform development of evidence-based and targeted prevention strategies for this high-risk population.

To date, research using the minority stress model has primarily explored the connections among sexual identity, discrimination, and health outcomes rather than accounting for multiple sexual orientation dimensions. Thus, the major objectives of this study were to: (i) examine the prevalence of DSM-5 AUD criteria as a function of sexual orientation, (ii) assess associations between sexual orientation discrimination and DSM-5 AUD severity among sexual minorities, and (iii) examine potential variations in these associations based on sex and sexual orientation dimensions.

\section{MATERIALS AND METHODS}

\section{Study Design}

The 2012 to 2013 National Epidemiologic Survey on Alcohol and Related Conditions III (NESARC-III) included a nationally representative sample from the general civilian noninstitutionalized population of U.S. adults aged 18 years and older $(N=36,309)$. The Alcohol Use Disorder and Associated Disabilities Interview Schedule-5 (AUDADIS-5) is a structured diagnostic interview and was used to conduct in-person interviews in households. The household response rate was $72 \%$, the person response rate was $84 \%$, and the overall response rate was $60 \%$. The NESARC-III study design is described in more detail elsewhere; all procedures received full human subjects review and institutional review board approval (Grant et al., 2015a, NESARC-III source statement).

Using NESARC-III data, approximately $66.2 \%$ of the population was estimated to identify as White, $11.8 \%$ as African American, 5.7\% as Asian, $14.7 \%$ as Hispanic, and $1.6 \%$ as Native American or another race/ethnicity. After applying the final survey weights, approximately $2.8 \%$ of the population self-identified as lesbian, gay, or bisexual; $3.1 \%$ reported at least 1 same-sex sexual partner in the past year; and $8.3 \%$ of the population reported same-sex sexual attraction. An estimated $8.9 \%(\mathrm{SE}=0.24)$ identified as a sexual minority based on at least 1 of the 3 sexual orientation dimensions. Slightly more women than men endorsed same-sex sexual attraction and sexual identity while slightly more men endorsed same-sex sexual behavior.

\section{Measures}

Past-year DSM-5 AUD and AUD severity were assessed according to criteria of the DSM-5 using the AUDADIS-5. Consistent with the DSM-5, a past-year AUD diagnosis was based on the presence of at least 2 of the 11 DSM-5 criteria (American Psychiatric Association, 2013; Hasin et al., 2013); past-year nondrinkers and lifetime abstainers, originally coded as having missing values on the 11 DSM-5 criteria in the NESARC-III data, had the missing values overwritten with responses of "no" prior to variable creation and analysis. The AUD criteria were grouped into the following 4 categories based on the DSM-5 (American Psychiatric Association, 2013): (i) impaired control (e.g., drank more or longer than intended, tried unsuccessfully to cut down, spent a lot of time drinking, or craving); (ii) social impairment (e.g., role interference, family/friend problems, or gave up activities); (iii) risky use (e.g., drank in risky situations or alcohol-related health problems); and (iv) 
pharmacologic (e.g., tolerance or withdrawal). An AUD severity scale was created by summing yes/no responses to the 11 criteria (range: 0 to 11 ). Reliability and validity of the DSM-5-based diagnoses of AUD have been examined previously (e.g., Grant et al., 2015b,c; Hasin et al., 2015). DSM-5 AUD criteria scales demonstrated excellent reliability (intraclass correlation coefficient $=0.9$ ) in a large population sample (Grant et al., 2015c). Small counts of "unknown" responses on the 11 DSM-5 criteria were handled in 2 ways: left as missing or replaced with a "no" response. These alternatives did not have any substantial impact on the analysis, and all reported analyses are based on the latter approach.

Sexual orientation discrimination was based on questions from the Experiences of Discrimination scale (Krieger and Sidney, 1997; Krieger et al., 2005). The sexual orientation discrimination measure assessed 6 different types of discrimination that respondents may have experienced because they were assumed to be a sexual minority (e.g., obtaining health care, receiving health care, obtaining a job, applying to school, interacting with police, public locations, and verbal or physical aggression). The range of responses for each item was never (0) to very often (4). Two scales were created by summing responses to the 6 items for prior-to-past-year and past-year discrimination, and each scale ranged from 0 to 24 (McCabe et al., 2010; Ruan et al., 2008). Both sexual orientation discrimination scales had excellent reliability based on data from the NESARC-II (Cronbach's alphas $=0.84$ and 0.81; Ruan et al., 2008) and the NESARC-III (Cronbach's alphas $=0.88$ and 0.89; McCabe et al., 2017).

Sociodemographic/background characteristics and other covariates included sex, age, race/ethnicity, educational status, urbanicity, and geographical region. Sexual orientation subgroups were created based on prior research (e.g., Drabble et al., 2005; Trocki et al., 2009 ) by combining the 3 sexual orientation dimensions into the following 5 mutually exclusive sexual orientation subgroups: (i) lesbian/gay-identified; (ii) bisexual-identified; (iii) unsure of their sexual identity; (iv) heterosexual-identified with same-sex attraction and/or behavior; and (v) heterosexual-identified without same-sex attraction or behavior. History of household substance-related problems was assessed by asking respondents whether a parent or other adult living in their home had an alcohol or drug problem before respondents were 18 years of age (Ruan et al., 2008).

Other past-year DSM-5 substance use disorders (SUDs) were assessed using DSM-5-based AUDADIS-5 criteria for drug-specific diagnoses related to 9 substances: cannabis, cocaine, heroin, hallucinogens, inhalants, prescription opioids, sedatives/tranquilizers, stimulants, and other drugs (e.g., ecstasy and ketamine). Consistent with past-year AUD, each DSM-5 SUD diagnosis required positive responses to 2 or more of the 11 criteria in the 12 months preceding the interview for each drug-specific SUD. Other DSM-5 mental health disorders were assessed using the AUDADIS-5, including lifetime antisocial personality and conduct disorders. Reliability and validity of the DSM-5-based AUDADIS-5 diagnoses of substance use and other mental health disorders have been established in numerous psychometric studies (Grant et al., 2015c, 2016; Hasin et al., 2015).

\section{Statistical Analysis}

All statistical analyses were design-based and incorporated the complex design features of the NESARC-III sample, including stratification of the target population, multistage cluster sampling, and weighting to compensate for unequal probabilities of selection and differential nonresponse across population subgroups (for more information about the NESARC-III survey weight calculations, see Grant et al., 2015a). We used Stata software (Version 15.1; StataCorp LLC, College Station, TX), specifically the "svy" suite of commands, to perform all designbased analyses. Variance estimates were computed using Taylor series linearization to reflect the complex sampling features (stratification, cluster sampling, and weighting) in the estimates of sampling variance.

We began with descriptive analyses, first estimating the probability of endorsing each of the 11 individual DSM-5 AUD criteria among men and women, overall and separately for each of the 5 sexual orientation subgroups (as defined in the Measures section). Next, we focused on the subpopulation of individuals who met criteria for past-year AUD (i.e., those reporting 2 or more DSM-5 AUD criteria; American Psychiatric Association, 2013) and estimated percentages of men and women (overall and by sexual orientation subgroup) who endorsed each of the 11 individual AUD criteria. Sexual orientation subgroup differences were tested using designadjusted Rao-Scott tests of association (Rao and Scott, 1984; Rao and Thomas, 1988). Finally, we estimated the percentages of men and women who endorsed various criteria groupings based on the DSM-5 (i.e., impaired control, social impairment, risky use, and pharmacologic).

Next, we fit multivariable regression models to examine associations between past-year sexual orientation discrimination and AUD severity and criteria groupings, adjusting for other relevant covariates. First, among respondents who were asked about past-year sexual orientation discrimination, we began with a linear regression model for past-year AUD severity (with discrete values ranging from 0 to 11$)$. Given that the distribution of this criteria count variable included a large number of zeros, we also tested Poisson and negative binomial regression models to evaluate model fit and robustness of the estimated relationships. We controlled for sex, race/ethnicity, age, education, urbanicity, region of the United States, indicators of any lifetime antisocial or conduct disorders, any history of a parent or other adult in the household with substance-related problems, and any indicators of other past-year drug use disorders in each of these models. To determine whether the relationship between AUD severity and past-year sexual orientation discrimination was moderated by sex or sexual orientation, we also tested 2-way interactions between sex and sexual orientation subgroups with sexual orientation discrimination in each of the AUD severity models.

Finally, we fit 5 design-based binary logistic regression models to the 5 indicators of different criteria groupings (which were not mutually exclusive), including the same covariates and interaction terms and focusing on the relationship of past-year sexual orientation discrimination with the probability of endorsing each type of AUD in the past year. Given the number of analyses performed, we considered $p<0.01$ to be indicative of statistical significance (Benjamin et al., 2018).

\section{RESULTS}

\section{Prevalence of Past-Year DSM-5 AUD Criteria by Sex and Sexual Orientation: Overall Population}

Table 1 shows the estimated probabilities of endorsing each of the past-year DSM-5 AUD criteria among U.S. adults aged 18 years and older based on sexual orientationseparately for men and women - in the overall population. Among men, the 5 sexual orientation subgroups varied significantly $(p<0.01)$ in endorsement of 8 of the 11 AUD criteria, whereas among women, the 5 subgroups varied significantly on all 11 AUD criteria. Furthermore, the differences among subgroups tended to be larger among women than among men. Individuals who identified as bisexual or those unsure of their sexual identity had the highest 


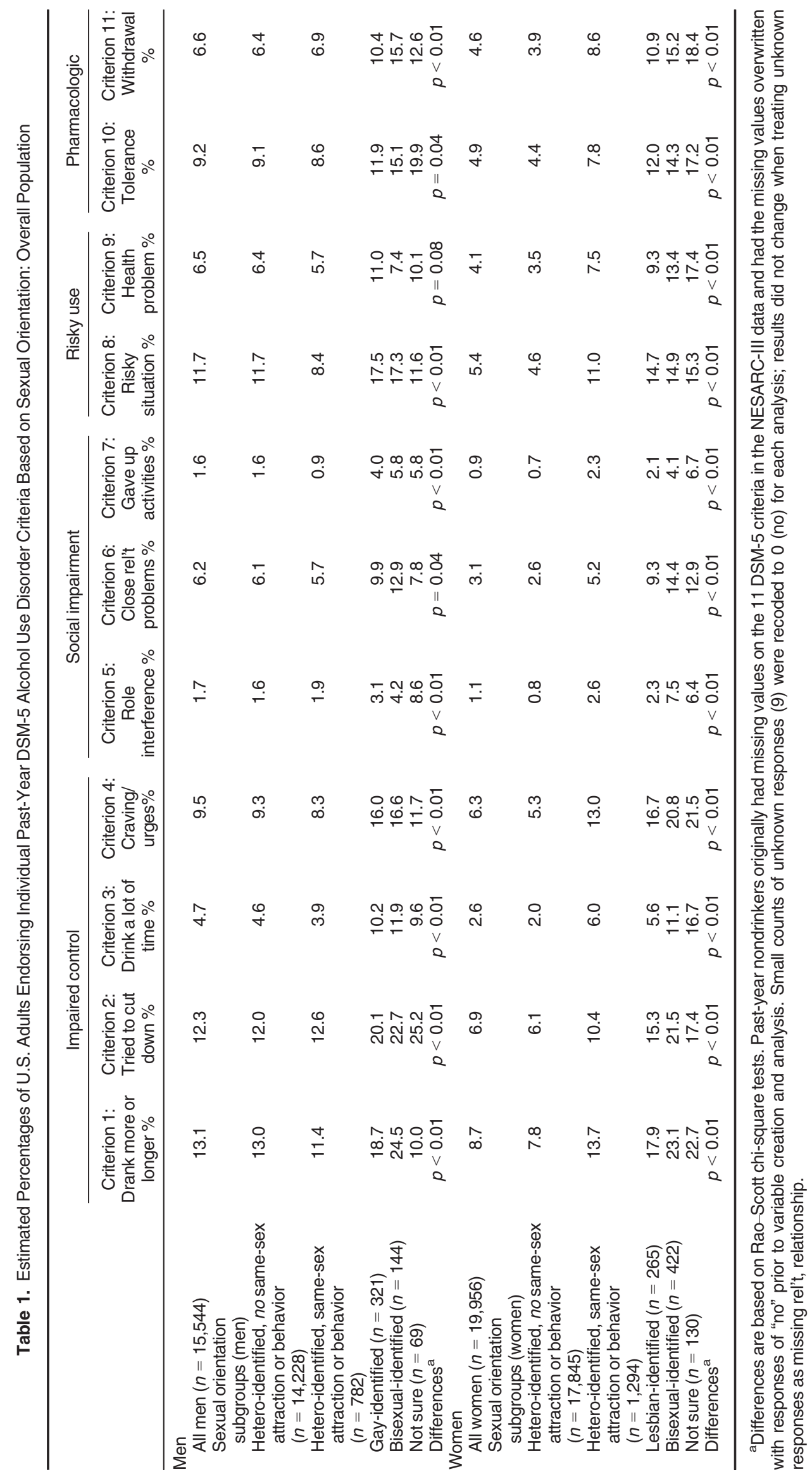


probabilities of endorsing each of the criteria relative to the other subgroups, especially among women.

Based on the overall sample, the 5 sexual orientation subgroups tended to vary significantly in terms of the probabilities of endorsing the DSM-5 AUD criteria groupings (i.e., impaired control, social impairment, risky use, and pharmacologic criteria). Bisexual men and women tended to have the highest probabilities of endorsing most AUD criteria groupings (Table 2). Notably, heterosexual-identified women who reported same-sex behavior had a higher probability than bisexual women of reporting criteria related to risky alcohol use. Further, although there were several significant associations between sexual orientation and criteria groupings among both men and women, sexual orientation subgroup differences tended to be much larger among women, particularly when comparing the heterosexuals with no same-sex attraction or behavior to the other 4 subgroups. Similarly, we found that the 5 subgroups varied in terms of AUD severity (see Table S1).

We also examined the estimated percentages of men and women in the overall population and in each sexual orientation subgroup who met criteria for past-year DSM-5 AUD (see Table S1). The past-year prevalence of DSM-5 AUD did not differ significantly between heterosexual-identified men with no same-sex attraction or behavior $(17.1 \%)$ and heterosexual-identified men with same-sex attraction or behavior $(14.5 \%)$, but was elevated among bisexual men (31.4\%), gay men $(26.2 \%)$, and men who were unsure of their sexual identity $(23.7 \%, p<0.01)$. In contrast, past-year DSM-5 AUD was much less prevalent among heterosexual-identified women with no same-sex attraction or behavior $(8.8 \%)$ than among bisexual women (29.3\%), lesbian women (24.5\%), and heterosexual-identified women with same-sex attraction or behavior $(18.8 \%, p<0.01)$. The sample sizes reported in Table S1 represent the NESARC-III subsamples for each sex-specific sexual orientation category (e.g., there were 14,228 men in the NESARC-III sample who identified as heterosexual with no same-sex attraction or behavior). The probability of having a more severe AUD (based on a count of criteria) tended to be larger for bisexual respondents and those unsure of their sexual identity. In addition, differences across sexual orientation subgroups were again larger for women than for men. In particular, bisexual women were nearly 3 times as likely as heterosexual women with no samesex attraction or behavior to meet criteria for any AUD.

\section{Prevalence of Past-Year DSM-5 AUD Criteria by Sex and Sexual Orientation: Subpopulation of Respondents with a Past-Year AUD}

Among the subpopulation of U.S. adults who met criteria for a past-year AUD, we examined the prevalence of individual criteria across sexual orientation subgroups, separately for men and women (see Table S2). Among men with a pastyear AUD, the 5 sexual orientation subgroups did not vary significantly in the probability of endorsing any of the 11 AUD criteria. However, among women with a past-year AUD, we found statistically significant differences in

Table 2. Estimated Percentages of U.S. Adults Endorsing at Least 1 Criteria from Past-Year DSM-5 Alcohol Use Disorder (AUD) Criteria Groupings Based on Sexual Orientation: Overall Population

\begin{tabular}{|c|c|c|c|c|c|}
\hline & $\begin{array}{l}\text { No AUD criteria } \\
\text { (no criteria) } \%\end{array}$ & $\begin{array}{l}\text { Impaired control } \\
\text { (at least } 1 \text { criteria; } \\
\text { criteria \#1 - \#4) \% }\end{array}$ & $\begin{array}{l}\text { Social impairment } \\
\text { (at least } 1 \text { criteria; } \\
\text { criteria \#5 - \#7) \% }\end{array}$ & $\begin{array}{c}\text { Risky use } \\
\text { (at least } 1 \text { criteria; } \\
\text { criteria \#8 - \#9) \% }\end{array}$ & $\begin{array}{c}\text { Pharmacologic } \\
\text { (at least } 1 \text { criteria; } \\
\text { criteria \#10 - \#11)\% }\end{array}$ \\
\hline \multicolumn{6}{|l|}{ Men } \\
\hline All men ( $n=15,544)$ & 71.9 & 22.1 & 7.0 & 14.5 & 12.5 \\
\hline $\begin{array}{l}\text { Sexual orientation subgroups } \\
\text { Heterosexual-identified, no same-sex } \\
\text { attraction or behavior }(n=14,228)\end{array}$ & 72.2 & 21.7 & 6.9 & 14.5 & 12.3 \\
\hline $\begin{array}{l}\text { Heterosexual-identified, same-sex } \\
\text { attraction or behavior }(n=782)\end{array}$ & 73.4 & 21.3 & 7.0 & 10.9 & 12.1 \\
\hline Gay-identified $(n=321)$ & 60.4 & 33.0 & 12.2 & 20.8 & 16.7 \\
\hline Bisexual-identified $(n=144)$ & 59.0 & 38.4 & 14.1 & 20.2 & 21.5 \\
\hline Not sure $(n=69)$ & 67.9 & 27.9 & 10.3 & 13.1 & 21.6 \\
\hline Differences $^{\mathrm{a}}$ & $p<0.01$ & $p<0.01$ & $p=0.01$ & $p<0.01$ & $p=0.02$ \\
\hline \multicolumn{6}{|l|}{ Women } \\
\hline $\begin{array}{l}\text { All women }(n=19,956) \\
\text { Sexual orientation subgroups }\end{array}$ & 82.0 & 14.0 & 3.6 & 7.7 & 7.7 \\
\hline $\begin{array}{l}\text { Heterosexual-identified, no same-sex } \\
\text { attraction or behavior }(n=17,845)\end{array}$ & 83.5 & 12.7 & 3.0 & 6.6 & 6.8 \\
\hline $\begin{array}{l}\text { Heterosexual-identified, same-sex } \\
\text { attraction or behavior }(n=1,294)\end{array}$ & 72.2 & 22.1 & 6.5 & 15.1 & 12.9 \\
\hline Lesbian-identified $(n=265)$ & 68.6 & 27.5 & 10.1 & 18.9 & 18.2 \\
\hline Bisexual-identified $(n=422)$ & 57.1 & 35.3 & 15.0 & 22.4 & 21.6 \\
\hline Not sure $(n=130)$ & 64.8 & 32.0 & 13.1 & 21.5 & 22.9 \\
\hline Differences $^{a}$ & $p<0.01$ & $p<0.01$ & $p<0.01$ & $p<0.01$ & $p<0.01$ \\
\hline
\end{tabular}

${ }^{\mathrm{a} D i f f e r e n c e s}$ are based on Rao-Scott chi-square tests. Past-year nondrinkers originally had missing values on the 11 DSM- 5 criteria in the NESARC-III data and had the missing values overwritten with responses of "no" prior to variable creation and analysis. Small counts of unknown responses (9) were recoded to 0 (no) for each analysis; results did not change when treating unknown responses as missing. 
Table 3. Regression Models for Past-Year DSM-5 Alcohol Use Disorder (AUD) Severity as a Function of Sexual Orientation Discrimination: Subpopulation of U.S. Sexual Minorities Asked About Sexual Orientation Discrimination

\begin{tabular}{|c|c|c|c|c|}
\hline \multirow[b]{2}{*}{ Covariates } & \multicolumn{2}{|c|}{ Linear regression } & \multicolumn{2}{|c|}{ Negative binomial regression (log link) } \\
\hline & $\begin{array}{l}\text { Model 1: Past-year DSM-5 } \\
\text { AUD severity as a function } \\
\text { of past-year sexual orientation } \\
\text { discrimination; } n=3,463 \\
\text { Estimated coefficient } \\
{[95 \% \mathrm{Cl}]}\end{array}$ & $\begin{array}{l}\text { Model 2: Past-year DSM-5 } \\
\text { AUD severity as a function of } \\
\text { PPY sexual orientation } \\
\text { discrimination; } n=3,460 \\
\text { Estimated coefficient } \\
{[95 \% \mathrm{Cl}]}\end{array}$ & $\begin{array}{l}\text { Model 3: Past-year DSM-5 AUD } \\
\text { severity as a function } \\
\text { of past-year sexual orientation } \\
\text { discrimination; } n=3,463 \\
\text { Estimated coefficient } \\
{[95 \% \mathrm{Cl}]}\end{array}$ & $\begin{array}{l}\text { Model 4: Past-year } \\
\text { DSM-5 AUD severity } \\
\text { as a function of PPY } \\
\text { sexual orientation } \\
\text { discrimination; } n=3,460 \\
\text { Estimated coefficient } \\
{[95 \% \mathrm{Cl}]}\end{array}$ \\
\hline Intercept & $0.02[-0.24,0.28]$ & $0.01[-0.25,0.27]$ & $-1.99[-2.53,-1.44]^{\star *}$ & $-2.00[-2.56,-1.44]^{\star *}$ \\
\hline $\begin{array}{l}\text { Sexual orientation } \\
\text { discrimination scale }\end{array}$ & $0.07[0.02,0.12]^{*}$ & $0.04[<0.01,0.07]$ & $0.06[0.02,0.10]^{*}$ & $0.04[0.01,0.07]$ \\
\hline \multicolumn{5}{|l|}{ Sex } \\
\hline Male & - & - & - & - \\
\hline Female & $-0.12[-0.30,0.06]$ & $-0.12[-0.30,0.06]$ & $-0.19[-0.35,-0.03]$ & $-0.19[-0.35,-0.03]$ \\
\hline \multicolumn{5}{|l|}{ Race/ethnicity } \\
\hline White & - & - & - & - \\
\hline Black & $0.18[-0.06,0.42]$ & $0.19[-0.05,0.44]$ & $0.12[-0.08,0.33]$ & $0.14[-0.07,0.34]$ \\
\hline Hispanic & $-0.06[-0.28,0.16]$ & $-0.04[-0.26,0.18]$ & $-0.17[-0.38,0.04]$ & $-0.16[-0.37,0.05]$ \\
\hline Other & $-0.01[-0.28,0.27]$ & $<0.01[-0.27,0.27]$ & $-0.08[-0.37,0.21]$ & $-0.06[-0.35,0.22]$ \\
\hline \multicolumn{5}{|l|}{ Age } \\
\hline $65+$ & - & - & - & - \\
\hline 45 to 64 & $0.32[0.15,0.48]^{\star *}$ & $0.33[0.16,0.49]^{\star *}$ & $1.21[0.76,1.65]^{\star \star}$ & $1.22[0.78,1.65]^{\star \star}$ \\
\hline 25 to 44 & $0.73[0.55,0.91]^{\star \star}$ & $0.74[0.56,0.92]^{\star \star}$ & $1.65[1.20,2.09]^{\star \star}$ & $1.66[1.22,2.10]^{\star \star}$ \\
\hline 18 to 24 & $1.04[0.83,1.25]^{\star *}$ & $1.06[0.85,1.28]^{\star *}$ & $1.88[1.44,2.32]^{\star \star}$ & $1.90[1.47,2.34]^{\star \star}$ \\
\hline \multicolumn{5}{|l|}{ Education } \\
\hline HS or less & - & - & - & - \\
\hline GED/some coll. & $0.18[-0.01,0.38]$ & $0.18[-0.02,0.37]$ & $0.19[0.02,0.36]$ & $0.18[0.01,0.36]$ \\
\hline College grad + & $0.13[-0.09,0.34]$ & $0.11[-0.10,0.33]$ & $0.15[-0.05,0.36]$ & $0.13[-0.07,0.34]$ \\
\hline \multicolumn{5}{|l|}{ Urbanicity } \\
\hline Urban & - & - & - & - \\
\hline Rural & $-0.21[-0.45,0.03]$ & $-0.21[-0.45,0.03]$ & $-0.29[-0.60,0.03]$ & $-0.28[-0.60,0.03]$ \\
\hline \multicolumn{5}{|l|}{ Geographical region } \\
\hline Northeast & - & - & - & - \\
\hline Midwest & $-0.05[-0.32,0.21]$ & $-0.04[-0.31,0.22]$ & $-0.02[-0.29,0.26]$ & $-0.01[-0.29,0.26]$ \\
\hline South & $-0.22[-0.47,0.03]$ & $-0.21[-0.46,0.04]$ & $-0.15[-0.37,0.07]$ & $-0.14[-0.37,0.09]$ \\
\hline West & $-0.01[-0.26,0.25]$ & $-0.01[-0.26,0.25]$ & $0.08[-0.16,0.31]$ & $0.07[-0.17,0.31]$ \\
\hline \multicolumn{5}{|c|}{ Any other past-year substance use disorder (SUD) } \\
\hline No past-year SUD & - & - & - & - \\
\hline Any other past-year SUD & $1.31[1.08,1.55]^{\star \star}$ & $1.32[1.09,1.56]^{\star \star}$ & $1.05[0.88,1.23]^{\star \star}$ & $1.06[0.88,1.23]^{\star \star}$ \\
\hline \multicolumn{5}{|c|}{ Lifetime conduct or antisocial disorder ${ }^{c}$} \\
\hline No disorder & - & - & - & - \\
\hline Conduct/antisocial disorder & $0.80[0.31,1.29]^{*}$ & $0.81[0.32,1.30]^{*}$ & $0.40[0.16,0.64]^{\star}$ & $0.39[0.15,0.64]^{*}$ \\
\hline \multicolumn{5}{|c|}{ Household history of substance problem by parent/adult } \\
\hline No household history & - & - & - & - \\
\hline Yes household history & $0.11[-0.12,0.34]$ & $0.10[-0.13,0.33]$ & $0.15[-0.03,0.34]$ & $0.16[-0.03,0.34]$ \\
\hline Don't know/missing/other & $-0.20[-1.16,0.76]$ & $-0.20[-1.16,0.76]$ & $-0.57[-1.58,0.44]$ & $-0.58[-1.59,0.43]$ \\
\hline $\begin{array}{l}\text { Overdispersion parameter } \\
\text { (for negative }^{\text {binomial models) }}{ }^{d}\end{array}$ & & & $2.80[2.49,3.15]^{\star \star}$ & $2.82[2.50,3.17]^{\star \star}$ \\
\hline $\begin{array}{l}R \text {-squared (for linear } \\
\text { regression models) }\end{array}$ & 0.163 & 0.161 & & \\
\hline
\end{tabular}

95\% Cl, confidence interval; - = reference group; PPY = prior-to-past-year.

${ }^{a}$ The sexual orientation discrimination scale in model 1 and model 3 consisted of past-year sexual orientation discrimination experiences $(0$ to 24$)$ while the sexual orientation discrimination scale in model 2 and model 4 consisted of PPY sexual orientation discrimination experiences (0 to 24).

${ }^{\mathrm{b}}$ Any other past-year DSM-5 other SUD consisted of cannabis, cocaine, heroin, hallucinogen, inhalant, prescription opioid, sedative/tranquilizer, stimulant, and/or other drug use disorder (e.g., ecstasy and ketamine).

${ }^{\circ}$ DSM- 5 conduct/antisocial personality disorder consisted of lifetime conduct disorder and/or antisocial personality disorder.

${ }^{\mathrm{d}}$ The overdispersion parameter captures the amount of additional variance above and beyond a Poisson distribution (where the mean of the dependent variable is equal to the variance of the dependent variable); if the reported confidence interval does not include zero, this suggests that the negative binomial model provides a better fit to the observed count data than the Poisson model.

${ }^{*} p \leq 0.01,{ }^{* *} p \leq 0.001$

endorsements of criterion 3 (spent a lot of time drinking), criterion 4 (craving/urges), criterion 5 (role interference), and criterion 6 (family/friend problems). Bisexual women and women unsure of their sexual identity consistently showed the highest probabilities of endorsing each of these criteria (3 through 6) relative to the other subgroups. Furthermore, 
women unsure of their sexual identity tended to have substantially higher probabilities of criteria 7 through 11 ; however, given the small subgroup sizes, these differences, while noteworthy, were only marginally significant (see Table S2).

\section{Past-Year DSM-5 AUD Severity as a Function of Sexual Orientation Discrimination: Subpopulation of Sexual Minorities}

Results of regression analyses for past-year AUD severity showed that, after adjusting for the covariates, past-year sexual orientation discrimination tended to be a stronger correlate than prior-to-past-year sexual orientation discrimination (see Table 3). As shown in Fig. 1 and Table 3, higher levels of past-year sexual orientation discrimination were associated with significantly greater AUD severity among sexual minority respondents, when adjusting for the covariates. We arrived at similar inferences about these relationships when using a negative binomial regression modeling approach. In addition, other past-year SUDs and lifetime conduct and antisocial personality disorders were associated with significantly greater AUD severity among sexual minority respondents, when adjusting for the covariates. No significant interactions were found involving sex or sexual orientation subgroups. Similarly, we found that higher levels of sexual orientation discrimination increased the probability of having mild AUD (2 to 3 symptoms), moderate AUD (4 to 5 symptoms), and severe AUD (6 or more symptoms) (see Fig. S1).

As shown in Table 4, there were similar associations between past-year sexual orientation discrimination and the probabilities of reporting the various AUD criteria groupings. Specifically, we found that greater levels of pastyear sexual orientation discrimination increased the odds of social impairment criteria and pharmacologic criteria (see Table 4; Fig. 2). None of the 2-way or 3-way interactions tested were significant at the $p<0.01$ level.

\section{DISCUSSION}

AUDs are among the most prevalent mental health disorders and contribute considerably to morbidity and mortality worldwide (Rehm et al., 2009; World Health Organization, 2014). This is the first study to use a nationally representative sample to examine the association between DSM-5 AUD severity and sexual orientation discrimination. The Institute of Medicine (2011) report on the health of sexual and gender minorities emphasized that the absence of explanatory frameworks hampers the ability to effectively prevent, mitigate, or treat AUD in high-risk vulnerable populations. Several reviews of the literature have concluded that sexual minorities are at greater risk of compromised mental health as a result of factors, such as discrimination and stress, related to their sexual minority status (Green and Feinstein, 2012; Institute of Medicine, 2011; Meyer 2003). To this end, we considered sexual orientation discrimination as a possible correlate of DSM-5 AUD severity. Our findings provide new evidence that sexual minorities who experience high levels of sexual orientation discrimination are at substantially increased risk of severe AUD.

It is estimated that over 30 million U.S. adults meet criteria for a past-year DSM-5 AUD and over 3 million global deaths were attributable to alcohol consumption in 2012 (Grant et al., 2015b; World Health Organization, 2014). In

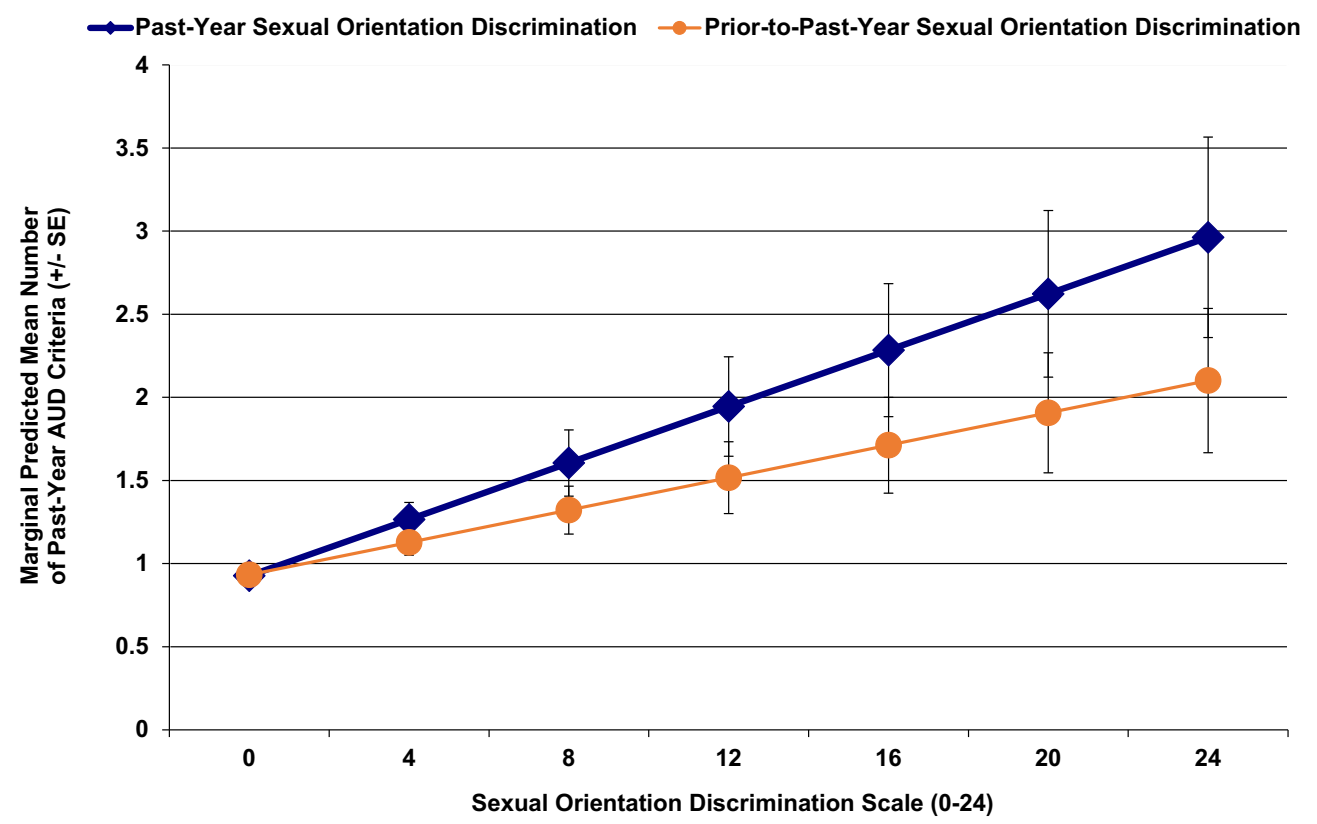

Fig. 1. Adjusted mean number of past-year DSM-5 alcohol use disorder (AUD) severity criteria as a function of past-year and prior-to-past-year sexual orientation discrimination (Source: NESARC-III). 
the current study, differences in DSM-5 AUD severity across sexual orientation subgroups were larger among women than among men. Overall, our results are consistent with those of other studies showing that lesbian and bisexual women are more likely than exclusively heterosexual (i.e., those report no same-sex behavior) women to report alcohol-related problems and that subgroup differences among men are smaller (Drabble et al., 2005; Hughes et al., 2016; McCabe et al., 2009, 2013). Previous studies have highlighted several factors that could account for such sex differences. These include adoption of nontraditional gender roles by sexual minorities, earlier age of drinking onset, higher rates of victimization among sexual minority women, and sex differences in drinking motivations and social venues (Hughes et al., 2016; McCabe et al., 2013; Trocki et al., 2005). Talley and colleagues (2015) found that women whose sexual

Table 4. Five Logit Models for Past-Year Groupings of DSM-5 Alcohol Use Disorder (AUD) Criteria Among Sexual Minorities

\begin{tabular}{|c|c|c|c|c|c|}
\hline Covariates & $\begin{array}{c}\text { No past-year DSM-5 } \\
\text { AUD criteria } \\
\text { AOR }[95 \% \mathrm{Cl}]\end{array}$ & $\begin{array}{c}\text { Past-year impaired control } \\
\text { AUD criteria }{ }^{\mathrm{a}} \\
\text { AOR }[95 \% \mathrm{Cl}]\end{array}$ & $\begin{array}{c}\text { Past-year social impairment } \\
\text { AUD criteria }{ }^{\mathrm{a}} \\
\text { AOR }[95 \% \mathrm{Cl}]\end{array}$ & $\begin{array}{l}\text { Past-year risky use } \\
\text { AUD criteria } \\
\text { AOR }[95 \% \mathrm{Cl}]\end{array}$ & $\begin{array}{c}\text { Past-year pharmacologic } \\
\text { AUD criteria }{ }^{a} \\
\text { AOR }[95 \% \mathrm{Cl}]\end{array}$ \\
\hline $\begin{array}{l}\text { Past-year sexual } \\
\text { orientation } \\
\text { discrimination scale }\end{array}$ & $0.96[0.93,1.00]$ & $1.03[1.00,1.08]$ & $1.07[1.02,1.12]^{\star}$ & $1.05[1.00,1.10]$ & $1.08[1.03,1.13]^{\star \star}$ \\
\hline \multicolumn{6}{|l|}{ Sex } \\
\hline Male & - & - & - & - & - \\
\hline Female & $1.37[1.10,1.70]^{*}$ & $0.75[0.60,0.93]^{*}$ & $0.74[0.52,1.05]$ & $0.91[0.73,1.14]$ & $0.80[0.61,1.04]$ \\
\hline \multicolumn{6}{|l|}{ Race/ethnicity } \\
\hline White & - & - & - & - & - \\
\hline Black & $0.88[0.68,1.15]$ & $1.18[0.90,1.54]$ & $1.33[0.94,1.90]$ & $1.02[0.75,1.39]$ & $1.55[1.15,2.07]^{*}$ \\
\hline Hispanic & $1.12[0.89,1.41]$ & $0.86[0.67,1.09]$ & $1.14[0.76,1.72]$ & $0.86[0.61,1.19]$ & $1.17[0.87,1.59]$ \\
\hline Other & $1.18[0.83,1.69]$ & $0.90[0.63,1.29]$ & $1.02[0.55,1.86]$ & $0.82[0.50,1.35]$ & $1.29[0.81,2.07]$ \\
\hline \multicolumn{6}{|l|}{ Age } \\
\hline $65+$ & - & - & - & - & - \\
\hline 45 to 64 & $0.43[0.28,0.65]^{\star *}$ & $2.84[1.69,4.75]^{\star \star}$ & $6.59[2.26,19.23]^{\star}$ & $3.14[1.54,6.40]^{*}$ & $2.35[1.24,4.45]^{*}$ \\
\hline 25 to 44 & $0.25[0.16,0.38]^{\star \star}$ & $5.35[3.07,9.35]^{\star \star}$ & $10.20[3.48,29.93]^{\star \star}$ & $5.15[2.55,10.39]^{\star \star}$ & $3.90[2.09,7.29]^{\star \star}$ \\
\hline 18 to 24 & $0.17[0.11,0.26]^{\star \star}$ & $6.78[3.83,11.99]^{\star *}$ & $13.28[4.47,39.43]^{\star \star}$ & $7.45[3.77,14.73]^{\star \star}$ & $6.97[3.73,13.02]^{\star *}$ \\
\hline \multicolumn{6}{|l|}{ Educational attainment } \\
\hline HS or less & - & - & - & - & - \\
\hline GED/some coll. & $0.83[0.67,1.03]$ & $1.25[0.98,1.59]$ & $0.98[0.71,1.34]$ & $1.44[1.13,1.83]^{\star}$ & $1.24[0.96,1.61]$ \\
\hline College grad + & $0.68[0.51,0.91]^{*}$ & $1.42[1.06,1.90]$ & $0.78[0.51,1.19]$ & $1.49[1.03,2.14]$ & $1.09[0.78,1.53]$ \\
\hline \multicolumn{6}{|l|}{ Urbanicity } \\
\hline Urban & - & - & - & - & - \\
\hline Rural & $1.41[1.00,2.00]$ & $0.72[0.52,1.00]$ & $0.93[0.53,1.63]$ & $0.71[0.50,1.00]$ & $0.72[0.50,1.04]$ \\
\hline \multicolumn{6}{|l|}{ Geographical region } \\
\hline Northeast & - & - & - & - & - \\
\hline Midwest & $1.08[0.76,1.54]$ & $0.79[0.54,1.15]$ & $1.06[0.65,1.74]$ & $1.02[0.68,1.51]$ & $1.07[0.67,1.71]$ \\
\hline South & $1.17[0.89,1.53]$ & $0.70[0.52,0.94]$ & $0.77[0.47,1.25]$ & $0.85[0.60,1.20]$ & $1.01[0.67,1.51]$ \\
\hline West & $0.81[0.60,1.10]$ & $1.20[0.86,1.66]$ & $1.00[0.62,1.63]$ & $0.96[0.67,1.36]$ & $1.07[0.70,1.65]$ \\
\hline \multicolumn{6}{|c|}{$\begin{array}{l}\text { Any other past-year substance } \\
\text { use disorder (SUD) }\end{array}$} \\
\hline No past-year SUD & - & - & - & - & - \\
\hline $\begin{array}{l}\text { Any other past- } \\
\text { year SUD }\end{array}$ & $0.33[0.27,0.40]^{\star *}$ & $3.03[2.43,3.79]^{\star \star}$ & $3.87[2.92,5.13]^{\star *}$ & $3.10[2.47,3.91]^{\star \star}$ & $3.44[2.67,4.43]^{\star *}$ \\
\hline \multicolumn{6}{|c|}{ Lifetime conduct or antisocial disorder $^{\mathrm{d}}$} \\
\hline No disorder & - & - & - & - & - \\
\hline $\begin{array}{l}\text { Conduct/antisocial } \\
\text { disorder }\end{array}$ & $0.76[0.54,1.05]$ & $1.40[1.00,1.98]$ & $2.28[1.51,3.42]^{\star *}$ & $1.26[0.90,1.77]$ & $1.61[1.11,2.33]$ \\
\hline \multicolumn{6}{|c|}{$\begin{array}{l}\text { Household history of substance } \\
\text { problem by parent/adult }\end{array}$} \\
\hline No household history & - & - & - & - & - \\
\hline Yes household history & $0.93[0.74,1.16]$ & $1.06[0.86,1.31]$ & $1.23[0.91,1.67]$ & $1.13[0.88,1.46]$ & $1.22[0.87,1.72]$ \\
\hline $\begin{array}{l}\text { Don't know/ } \\
\text { missing/other }\end{array}$ & $2.43[0.81,7.28]$ & $0.57[0.19,1.68]$ & $1.36[0.31,6.01]$ & $0.78[0.18,3.28]$ & $0.39[0.06,2.50]$ \\
\hline
\end{tabular}

AOR, odds ratio from logistic regression analyses adjusted for all covariates; $95 \% \mathrm{Cl}$, confidence interval. The sample size was 3,463 for each of the 5 logit models. - = reference group.

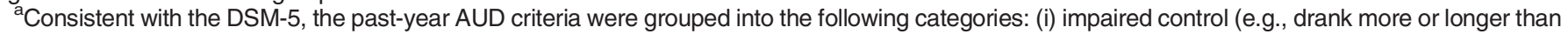
intended, tried unsuccessfully to cut down, spent a lot of time drinking, and craving); (ii) social impairment (e.g., role interference, family/friend problems, and gave up activities); (iii) risky use (e.g., drink in risky situations and alcohol-related health problems); and (iv) pharmacologic (e.g., tolerance and withdrawal) (American Psychiatric Association, 2013).

${ }^{b}$ Sexual orientation discrimination scale consisted of actual counts of past-year sexual orientation discrimination experiences (0 to 24).

${ }^{\mathrm{c}}$ Any other past-year DSM-5 other SUD consisted of cannabis, cocaine, heroin, hallucinogen, inhalant, prescription opioid, sedative/tranquilizer, stimulant, and/or other drug use disorder (e.g., ecstasy and ketamine).

${ }^{d}$ DSM-5 conduct/antisocial personality disorder consisted of lifetime conduct disorder and/or antisocial personality disorder.

${ }^{*} p \leq 0.01,{ }^{* *} p \leq 0.001$. 


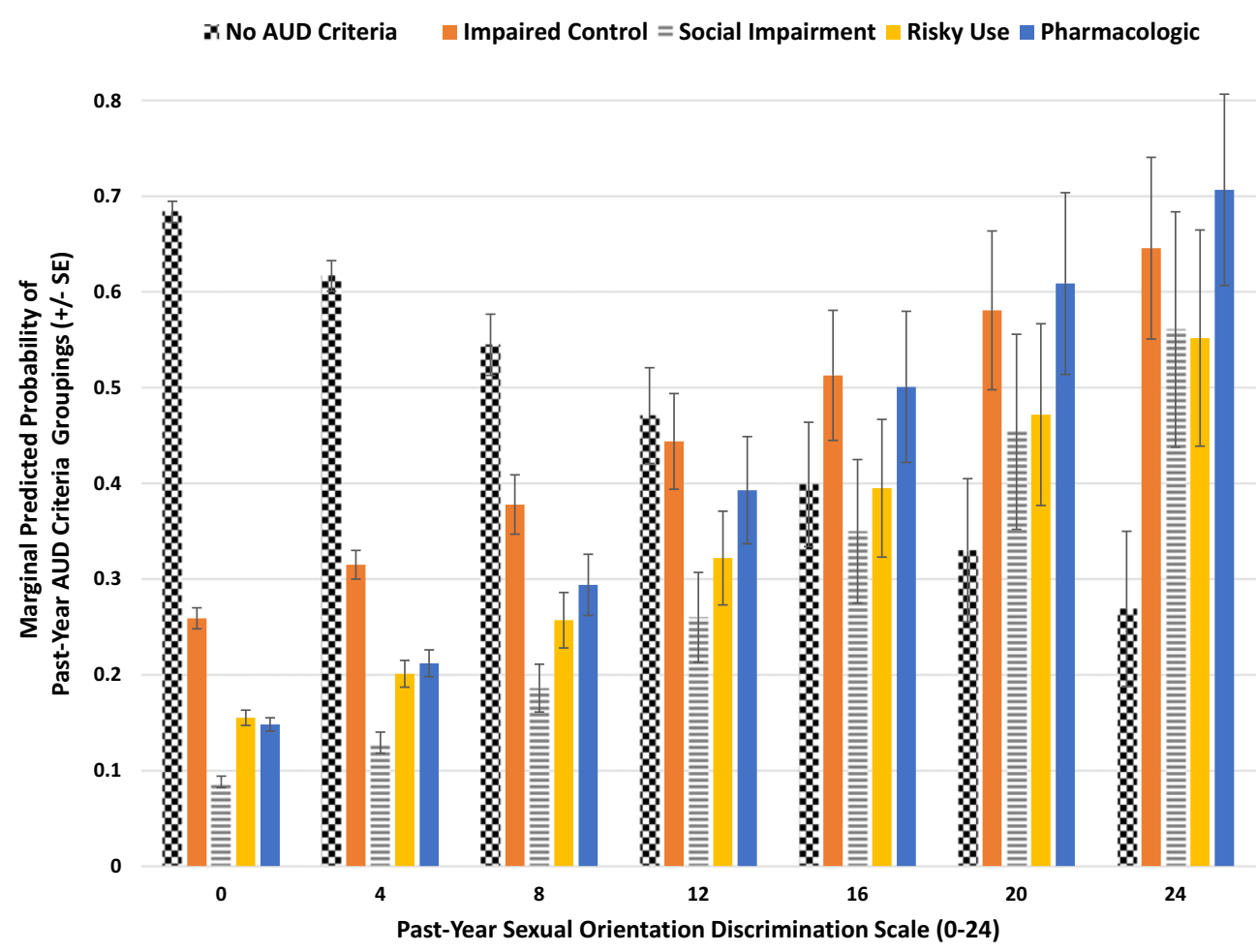

Fig. 2. Past-year DSM-5 alcohol use disorder (AUD) criteria groupings (impaired control, social impairment, risky use, pharmacologic criteria) as a function of past-year sexual orientation discrimination (Source: NESARC-III).

identity did not match their sexual behavior or sexual attraction were at increased risk of hazardous drinking. Our findings suggest that such discordance may operate differently for women and men and support the need for research aimed at understanding reasons for sex differences in the association between sexual orientation discordance and SUDs.

In the current study, even sexual minority adults who did not report past-year or prior-to-past-year sexual orientation discrimination had significantly higher rates of past-year DSM-5 AUD than exclusively heterosexual adults $(18.5 \%$ vs. $12.8 \%, p<0.01)$. This suggests that factors other than sexual orientation discrimination contribute to AUD among sexual minorities, or that the measures do not capture all forms of discrimination. For example, internalized homophobia, identity concealment, fear of rejection, and discrimination based on age, sex, or race/ethnicity (Himmelstein et al., 2015; Hughes et al., 2010a,b; McCabe et al., 2010; McLaughlin et al., 2009; Meyer, 1995, 2001, 2003; Rosario et al., 2009) may be important contributors to AUD risk. Unfortunately, these measures were not available in the NESARC-III. In addition, we found that other past-year SUDs and lifetime conduct or antisocial personality disorders were associated with significantly greater AUD severity and AUD symptoms among sexual minority respondents. These findings, along with prior work, highlight additional factors such as polysubstance use and psychiatric comorbidities that may need to be taken into account and tailored to the needs of sexual minorities in prevention and treatment planning (Bostwick et al., 2014; Kerridge et al., 2017; McCabe et al., 2009; Medley et al., 2016). Finally, we found that associations between prior-to-past-year sexual orientation discrimination and DSM-5 AUD severity were not as robust as past-year discrimination, suggesting that more proximal experiences of discrimination experiences involve greater risk of AUD than more distal experiences.

The present study has limitations that should be considered when weighing the implications of the results. First, the findings may underestimate DSM-5 AUD because the NESARC-III does not collect data from some subgroups (e.g., incarcerated individuals) with increased risk of AUD (Compton et al., 2010). Second, due to the cross-sectional design, causal inferences could not be made. Third, we focused on individual-level discrimination. Prior work has found that societal-level conditions that constrain individuals' opportunities, resources, and well-being are associated with heightened risk of psychiatric disorders among sexual minorities (Hatzenbuehler et al., 2009; Link and Phelan, 2001). Fourth, the NESARC-III did not include other measures such as gender identity, internalized homophobia, and family rejection that could be associated with DSM-5 AUD severity. Finally, lifetime AUD severity could not be determined based on data from the NESARC-III. Prospective research is needed to better understand the associations between AUD symptoms and sexual orientation given that sexual identity and AUD symptoms can change over time (Dawson et al., 2007; Diamond, 2008). Results of the present study also provide 
new evidence that U.S. adults who are unsure about their sexual identity are at heightened risk of AUD - a finding that warrants additional future research.

In conclusion, findings from this study provide evidence of heightened risk of severe DSM-5 AUD among sexual minorities relative to heterosexuals - and that this risk is compounded by sexual orientation-related discrimination. Risk of AUD was particularly evident among bisexual men and women and those unsure of their sexual identity. Further, differences in AUD severity across sexual orientation subgroups were much larger among women than among men. Higher levels of sexual orientation discrimination increased the odds of social impairment criteria and pharmacologic criteria. Such findings highlight the importance of prevention and early intervention strategies that take into account more severe AUD and recent sexual orientation discrimination experiences in efforts to reduce alcohol-use-related disparities based on sexual orientation.

\section{ACKNOWLEDGMENTS}

This manuscript was prepared using a limited access data set obtained from NIAAA and does not reflect the opinions or views of NIAAA or the U.S. Government. The authors would like to thank the anonymous reviewers for their constructive feedback and suggestions to an earlier version of the manuscript. The authors would also like to acknowledge the helpful assistance from Kara Dickinson with formatting and proofreading the manuscript.

\section{FUNDING}

This work was supported by research grants R01AA025684 and R01DA036541 (McCabe, PI) and R01DA043696 (Boyd, PI) from the National Institute on Alcohol Abuse and Alcoholism (NIAAA) and the National Institute on Drug Abuse (NIDA) at the National Institutes of Health (NIH). TLH is currently funded by a grant from NIAAA (R01AA013328). The funders had no role in the design and conduct of the study; collection, management, analysis, and interpretation of the data; preparation, review, or approval of the manuscript; and decision to submit the manuscript for publication. The content is solely the responsibility of the authors and does not necessarily represent the official views of the NIAAA, NIDA, NIH, or the U.S. Government.

\section{CONFLICT OF INTEREST}

None.

\section{REFERENCES}

American Psychiatric Association (2013) Diagnostic and Statistical Manual of Mental Disorders. 5th ed. American Psychiatric Publishing, Arlington, VA.
Benjamin DJ, Berger JO, Johannesson M, Nosek BA, Wagenmakers E-J, Berk R, Bollen KA, Brembs B, Brown L, Camerer C, Cesarini D, Chambers CD, Clyde M, Cook TD, De Boeck P, Dienes Z, Dreber A, Easwaran K, Eferson C, Fehr E, Fidler F, Field AP, Forster M, George EI, Gonzalez R, Goodman S, Green E, Green DP, Greenwald A, Hadfeld JD, Hedges LV, Held L, Ho TH, Hoijtink H, Hruschka DJ, Imai K, Imbens G, Ioannidis JPA, Jeon M, Holland Jones J, Kirchler M, Laibson D, List J, Little R, Lupia A, Machery E, Maxwell SE, McCarthy M, Moore D, Morgan SL, Munafó M, Nakagawa S, Nyhan B, Parker TH, Pericchi L, Perugini M, Rouder J, Rousseau J, Savalei V, Schönbrodt FD, Sellke T, Sinclair B, Tingley D, Van Zandt T, Vazire S, Watts DJ, Winship C, Wolpert RL, Xie Y, Young C, Zinman J, Johnson VE (2018) Redefine statistical significance. Nat Hum Behav 2:6-10.

Bostwick WB, Boyd CJ, Hughes TL, West BT, McCabe SE (2014) Discrimination and mental health among a national sample of lesbian, gay and bisexual adults. Am J Orthopsychiatry 84:35-45.

Cochran SD, Mays VM (2006) Estimating prevalence of mental and substance-using disorders among lesbians and gay men from existing national health data, in Sexual Orientation and Mental Health: Examining Identity and Development in Lesbian, Gay, and Bisexual People (Omoto AM, Kurtzman HS eds), pp 143-165. APA Books, Washington DC.

Cochran SD, Mays VM, Sullivan JG (2003) Prevalence of mental disorders, psychological distress, and mental health services use among lesbian, gay, and bisexual adults in the United States. J Consult Clin Psychol 71:53-61.

Compton WM, Dawson D, Duffy SQ, Grant BF (2010) The effect of inmate populations on estimates of DSM-IV alcohol and drug use disorders in the United States. Am J Psychiatry 167:473-474.

Dawson DA, Goldstein RB, Grant BF (2007) Rates and correlates of relapse among individuals in remission from DSM-IV alcohol dependence: a 3year follow-up. Alcohol Clin Exp Res 31:2036-2045.

Diamond LM (2008) Sexual Fluidity: Understanding Women's Love and Desire. Harvard University Press, Cambridge, MA.

Drabble L, Midanik LT, Trocki K (2005) Reports of alcohol consumption and alcohol-related problems among homosexual, bisexual, and heterosexual respondents: results from the 2000 National Alcohol Survey. J Stud Alcohol 66:111-120.

Drabble L, Trocki KF, Hughes TL, Korcha RA, Lown AE (2013) Sexual orientation differences in the relationship between victimization and hazardous drinking among women in the National Alcohol Survey. Psychol Addict Behav 27:639-648.

Eisenberg M, Wechsler H (2003) Substance use behaviors among college students with same-sex and opposite-sex experience: results from a national study. Addict Behav 28:899-913.

Grant BF, Chu A, Sigman R, Amsbary M, Kali J, Sugawara Y, Jiao R, Ren W, Goldstein R (2015a) Source and Accuracy Statement for the National Epidemiologic Survey on Alcohol and Related Conditions-III (NESARCIII). National Institute on Alcohol Abuse and Alcoholism, Rockville, MD.

Grant BF, Goldstein RB, Saha TD, Chou SP, Jung J, Zhang H, Pickering RP, Ruan WJ, Smith SM, Huang B, Hasin DS (2015b) Epidemiology of DSM-5 alcohol use disorder: results from the National Epidemiologic Survey on Alcohol and Related Conditions III. J Am Med Assoc Psychiatry 72:757-766.

Grant BF, Goldstein RB, Smith SM, Jung J, Zhang H, Chou SP, Pickering RP, Ruan WJ, Huang B, Saha TD, Aivadyan C, Greenstein E, Hasin DS (2015c) The Alcohol Use Disorder and Associated Disabilities Interview Schedule-5 (AUDADIS-5): reliability of substance use and psychiatric disorder modules in a general population sample. Drug Alcohol Depend 148:27-33.

Grant BF, Saha TD, Ruan WJ, Goldstein RB, Chou SP, Jung J, Zhang H, Smith SM, Pickering RP, Huang B, Hasin DS (2016) Epidemiology of DSM-5 drug use disorder: results from the National Epidemiologic Survey on Alcohol and Related Conditions-III. J Am Med Assoc Psychiatry 73:39-47.

Green KE, Feinstein BA (2012) Substance use in lesbian, gay, and bisexual populations: an update on empirical research and implications for treatment. Psychol Addict Behav 26:265-278. 
Hasin DS, Greenstein E, Aivadyan C, Stohl M, Aharonovich E, Saha T, Goldstein R, Nunes EV, Jung J, Zhang H, Grant BF (2015) The Alcohol Use Disorder and Associated Disabilities Interview Schedule-5 (AUDADIS-5): procedural validity of substance use disorders modules through clinical re-appraisal in a general population sample. Drug Alcohol Depend 148:40-46.

Hasin DS, O'Brien CP, Auriacombe M, Borges G, Bucholz K, Budney A, Compton WM, Crowley T, Ling W, Petry NM, Schuckit M, Grant BF (2013) DSM-5 criteria for substance use disorders: recommendations and rationale. Am J Psychiatry 170:834-851.

Hatzenbuehler ML, Keyes KM, Hasin DS (2009) State-level policies and psychiatric morbidity in lesbian, gay and bisexual populations. Am J Public Health 99:2275-2281.

Hatzenbuehler ML, McLaughlin KA, Keyes KM, Hasin DS (2010) The impact of institutional discrimination on psychiatric disorders in lesbian, gay and bisexual populations: a prospective study. Am J Public Health 100:452-459.

Herek GM (2009) Hate crimes and stigma-related experiences among sexual minority adults in the United States: prevalence estimates from a national probability sample. J Interpers Violence 24:54-74.

Himmelstein MS, Young DM, Sanchez DT, Jackson JS (2015) Vigilance in the discrimination-stress model for Black Americans. Psychol Health 30:253-267.

Hughes TL, Eliason M (2002) Substance use and abuse in lesbian, gay, bisexual and transgender populations. J Prim Prev 22:263-298.

Hughes TL, McCabe SE, Wilsnack SC, West BT, Boyd CJ (2010a) Victimization and substance use disorders in a national sample of heterosexual and sexual minority women and men. Addiction 105:2130-2140.

Hughes TL, Szalacha LA, Johnson TP, Kinnison KE, Wilsnack SC, Cho Y (2010b) Sexual victimization and hazardous drinking among heterosexual and sexual minority women. Addict Behav 35:1152-1156.

Hughes TL, Wilsnack SC, Kantor L (2016) The influence of gender and sexual orientation on alcohol use and alcohol-related problems: toward a global perspective. Alcohol Res 38:121-132.

Institute of Medicine (2011) The Health of Lesbian, Gay, Bisexual, and Transgender People: Building a Foundation for Better Understanding. National Academies Press, Washington DC.

Kerridge BT, Pickering RP, Saha TD, Ruan WJ, Chou SP, Zhang H, Jung J, Hasin DS (2017) Prevalence, sociodemographic correlates and DSM-5 substance use disorders and other psychiatric disorders among sexual minorities in the United States. Drug Alcohol Depend 170:8292.

Krieger N, Sidney S (1997) Prevalence and health implications of anti-gay discrimination: a study of black and white women and men in the CARDIA cohort. Coronary Artery Risk Development in Young Adults. Int J Health Serv 27:157-176.

Krieger N, Smith K, Naishadham D, Hartman C, Barbeau EM (2005) Experiences of discrimination: validity and reliability of a self-report measure for population health research on racism and health. Soc Sci Med 61:1576-1596.

Lee JH, Gamarel KE, Bryant KJ, Zaller ND, Operario D (2016) Discrimination, mental health, and substance use disorders among sexual minority populations. LGBT Health 3:258-265.

Lewis RJ, Derlega VJ, Griffin JL, Krowinski AC (2003) Stressors for gay men and lesbians: life stress, gay-related stress, stigma consciousness, and depressive symptoms. J Soc Clin Psychol 22:716-729.

Link BG, Phelan JC (2001) Conceptualizing stigma. Annu Rev Sociol 27:363-385.

Mays VM, Cochran SD (2001) Mental health correlates of perceived discrimination among lesbian, gay, and bisexual adults in the United States. Am J Public Health 91:1869-1876.

McCabe SE, Bostwick WB, Hughes TL, West BT, Boyd CJ (2010) The relationship between discrimination and substance use disorders among lesbian, gay and bisexual adults in the United States. Am J Public Health 100:1946-1952.
McCabe SE, Hughes TL, Bostwick W, Boyd CJ (2005) Assessment of difference in dimensions of sexual orientation: implications for substance use research in a college-age population. J Stud Alcohol 66:620-629.

McCabe SE, Hughes TL, Bostwick WB, West BT, Boyd CJ (2009) Sexual orientation, substance use behaviors, and substance dependence in the United States. Addiction 104:1333-1345.

McCabe SE, Hughes T, Boyd CJ (2004) Substance use and misuse: are bisexual women at greater risk? J Psychoactive Drugs 36:217-225.

McCabe SE, Hughes TL, Matthews AK, Lee JGL, West BT, Boyd CJ, Arslanian-Engoren C (2017) Sexual orientation discrimination and tobacco use disparities in the United States. Nicotine Tob Res doi: 10.1093/ntr/ntx283 [Epub ahead of print].

McCabe SE, West BT, Hughes TL, Boyd CJ (2013) Sexual orientation and substance abuse treatment utilization in the United States: results from a national survey. J Subst Abuse Treat 44:4-12.

McLaughlin KA, Hatzenbuehler ML, Keyes KM (2009) Responses to discrimination and psychiatric disorders among Black, Hispanic, and lesbian, gay, and bisexual individuals. Am J Public Health 100:14771484.

Medley G, Lipari RN, Bose J, Cribb DS, Kroutil LA, McHenry G (2016) Sexual orientation and estimates of adult substance use and mental health: results from the 2015 National Survey on Drug Use and Health. NSDUH Data Review. Available at: https://www.samhsa.gov/data/sites/default/ files/NSDUH-SexualOrientation-2015/NSDUH-SexualOrientation-2015/ NSDUH-SexualOrientation-2015.htm. Accessed January 27, 2019.

Meyer IH (1995) Minority stress and mental health in gay men. J Health Soc Behav 36:38-56.

Meyer IH (2001) Why lesbian, gay, bisexual, and transgender public health? Am J Public Health 91:856-859.

Meyer IH (2003) Prejudice, social stress, and mental health in lesbian, gay, and bisexual populations: conceptual issues and research evidence. Psychol Bull 129:674-697.

Rao JNK, Scott AJ (1984) On chi-squared tests for multi-way tables with cell proportions estimated from survey data. Ann Stat 12:46-60.

Rao JNK, Thomas DR (1988) The analysis of cross-classified data from complex sample surveys. Sociol Methodol 18:213-269.

Rehm J, Mathers C, Popova S, Thavorncharoensap M, Teerawattananon Y, Patra J (2009) Global burden of disease and injury and economic cost attributable to alcohol use and alcohol-use disorders. Lancet 373:22232233.

Rosario M, Schrimshaw EW, Hunter J (2009) Disclosure of sexual orientation and subsequent substance use and abuse among lesbian, gay, and bisexual youths: critical role of disclosure reactions. Psychol Addict Behav 23:175-184.

Ruan WJ, Goldstein RB, Chou SP, Smith SM, Saha TD, Pickering RP, Dawson DA, Huang B, Stinson FS, Grant BF (2008) The Alcohol Use Disorder and Associated Disabilities Interview Schedule-IV (AUDADIS-IV): reliability of new psychiatric diagnostic modules and risk factors in a general population sample. Drug Alcohol Depend 92:27-36.

Slater ME, Godette D, Huang B, Ruan WJ, Kerridge BT (2017) Sexual orientation-based discrimination, excessive alcohol use, and substance use disorders among sexual minority adults. LGBT Health 4:337-344.

Talley AE, Aranda F, Hughes TL, Everett B, Johnson TP (2015) Longitudinal associations among discordant sexual orientation dimensions and hazardous drinking in a cohort of sexual minority women. J Health Soc Behav 56:225-245.

Trocki KF, Drabble L, Midanik L (2005) Use of heavier drinking contexts among heterosexuals, homosexuals and bisexuals: results from a national household probability survey. J Stud Alcohol 66:105-110.

Trocki KF, Drabble LA, Midanik LT (2009) Tobacco, marijuana, and sensation seeking: comparisons across gay, lesbian, bisexual, and heterosexual groups. Psychol Addict Behav 23:620-631. 
World Health Organization (2014) Global Status Report on Alcohol and Health: 2014. Management of Substance Abuse, Department of Mental Health and Substance Abuse, Geneva, Switzerland. Available at: http://apps.who.int/iris/bitstream/10665/112736/1/9789240692763_eng.pdf. Accessed March 28, 2017.

\section{SUPPORTING INFORMATION}

Additional supporting information may be found online in the Supporting Information section at the end of the article.
Fig. S1. Past-year DSM-5 AUD severity as a function of past-year sexual orientation discrimination (Source: NESARC-III).

Table S1. Estimated percentages of U.S. adults endorsing past-year DSM-5 AUD severity as a function of sexual orientation: overall population.

Table S2. Estimated percentages of U.S. adults endorsing individual past-year DSM-5 AUD criteria based on sexual orientation: subpopulation of U.S. adults with a past-year AUD. 